\title{
Hypertension and Recurrent Hypokalaemia in Young Woman - A Case Report of Primary Hyperaldosteronism (Conn's Syndrome)
}

\author{
MD.NAZMUL HASAN ${ }^{1}$, MD.ABDUR RAHIM ${ }^{1}$, QUAZI MAMTAZ UDDIN AHMED ${ }^{1}$, \\ MD. SYEDUL ISLAM ${ }^{1}$, MD. RASUL AMIN ${ }^{2}$, MD. ATIKUR RAHMAN ${ }^{1}$, MD.NURUL AMIN ${ }^{1}$ \\ ${ }^{1}$ Department of Internal Medicine, Bangabandhu Sheikh Mujib Medical University, Dhaka-1000 \\ ${ }^{2}$ Department of cardiology, Bangabandhu Sheikh Mujib Medical University, Dhaka-1000
}

Address of the correspondence: Dr. Md. Nazmul Hasan, Assistant professor, Department of Internal Medicine, Bangabandhu Sheikh Mujib Medical University, Dhaka-1000,Email-nazmul_31st@yahoo.com

\begin{abstract}
Primary hyperaldosteronism is caused by most commonly due to aldosterone producing adenoma(conn's syndrome) or bilateral adrenal hyperplasia. Clinical features may be of different type which includes hypertension in young age or resistant hypertension, recurrent hypokalaemia and characterized by increased ratio of plasma aldosterone (ng/dl) to rennin ( $\mathrm{ng} / \mathrm{ml}$ per hour) activity. We report a case of young woman presented with hypertension and recurrent hypokalaemia.
\end{abstract}

Key words: primary hyperaldosteronism, recurrent hypokalaemia, adrenal adenoma

\section{Introduction}

Primary hyperaldosteronism is characterized by increased aldosterone secretion and suppressed rennin activity which would clinically manifested as hypertension, hypokalaemia and was first described by J. W. Connin $1955 .{ }^{1}$ Primary hyperaldosteronism is a cause of secondary hypertension withprevalence estimates of $5-13 \%$ of all patients withhypertension and now regarded as one of the common cause. ${ }^{2,3}$ The common causes of primary hyperaldosteronism are, aldosterone-producing adenoma (Conn'ssyndrome) or bilateral idiopathic hyperplasia and lesscommon causes are due to primary (unilateral) adrenal hyperplasia, aldosterone-producing adrenocortical carcinoma or familial hyperaldosteronism. ${ }^{4}$ Primary hyperaldosteronism can sometimes pose a diagnosticdilemma as the presentation may be very varied andmisleading. We report a case of a 24- year- old woman who presented with recurrent hypokalaemia which was difficult to correct and hypertension.

\section{Case report}

A 24 -year-old woman was admitted in internal medicine department of Bangabandhu Sheikh Mujb Medical University(BSMMU),Dkaka with onset of hypertension at the age of 19 years of age and recurrent all four limb weakness due to hypokalaemia for 9 months. Her blood pressure was well control with losartan potassium $50 \mathrm{mg}$ daily. But she developed weakness of all four limbs 9 months back and was found to be hypokalaemic since then, she had several episodes of hypokalaemia and the last one was three months ago and was put on oral potassium supplement but it was not fully correct in three months.
For two weaks, she developed severe weakness of the all four limbs and was admitted in BSMMU. The weakness had no relation with taking carbohydrate meal and alcohol and she had no family history of hyperetension and hypokalaemia. General physical examination revealed pulse -80 beat $/ \mathrm{min}$, blood pressure- $150 / 90 \mathrm{~mm}$ of $\mathrm{Hg}$, reaspiratory rate -16 breaths/min and examination of the nervous system reavealed only reduced muscle power of MRC grade 3/5 in all four limbs, all jerks were present and planter was flexor bilaterally.All other examination findings are normal. The investigations showed, serum electrolyte: sodium-142 mmol/1, potassium- $1.71 \mathrm{mmol} /$ 1, chloride-103.3 mmlo/l, magnesium-2.1 mg/dl, corrected calcium-9,3 mg/dl, albumin- $33 \mathrm{gm} / \mathrm{dl}$; urinary electrolyte:sodium- $200 \mathrm{mmol} / \mathrm{l}$, potassium- $91 \mathrm{mmol} / \mathrm{l}$, calcium- $165 \mathrm{mg} / \mathrm{dl}$ and serum creatinie $-1.3 \mathrm{mg} / \mathrm{dl}$. ECG showed prmonent $\mathrm{R}$ wave in $\mathrm{v}_{2}$, $\mathrm{ST}$-segment depression, $\mathrm{T}$ - wave inversion and pathological Q wave merged with $\mathrm{T}$ wave(figure-1)Urine RME, urinary $\mathrm{PH}$, LFT and ABG were normal. The USG of whole abdomen and echocardiogram were normal. Serum aldosterone and plasma renin were $379.10 \mathrm{pg} / \mathrm{ml}$ ( early morning, normal range: $20-180 \mathrm{pg} / \mathrm{ml}$ ) and $10 \mathrm{pg} / \mathrm{ml}$ ( normal range: 4$37.25 \mathrm{pg} / \mathrm{ml}$ ) respectively and aldosterone to renin ratio is 37.91. The CT -scan of adrenal glands with contrast showed left sided adrenal adenoma( figure-2). She was treated with oral and intravenous potassium supplement before diagnosis but never corrected until we added spiranolactone $100 \mathrm{mg}$ daily with losartan potassium 50 $\mathrm{mg}$ OD to control blood pressure. Now she is on this two drug without any potassium supplement and her potassium level was $4.3 \mathrm{mmol} / \mathrm{l}$. Simultaneously, we consulted surgeon and she is listed for left sided adrenallectomy. 


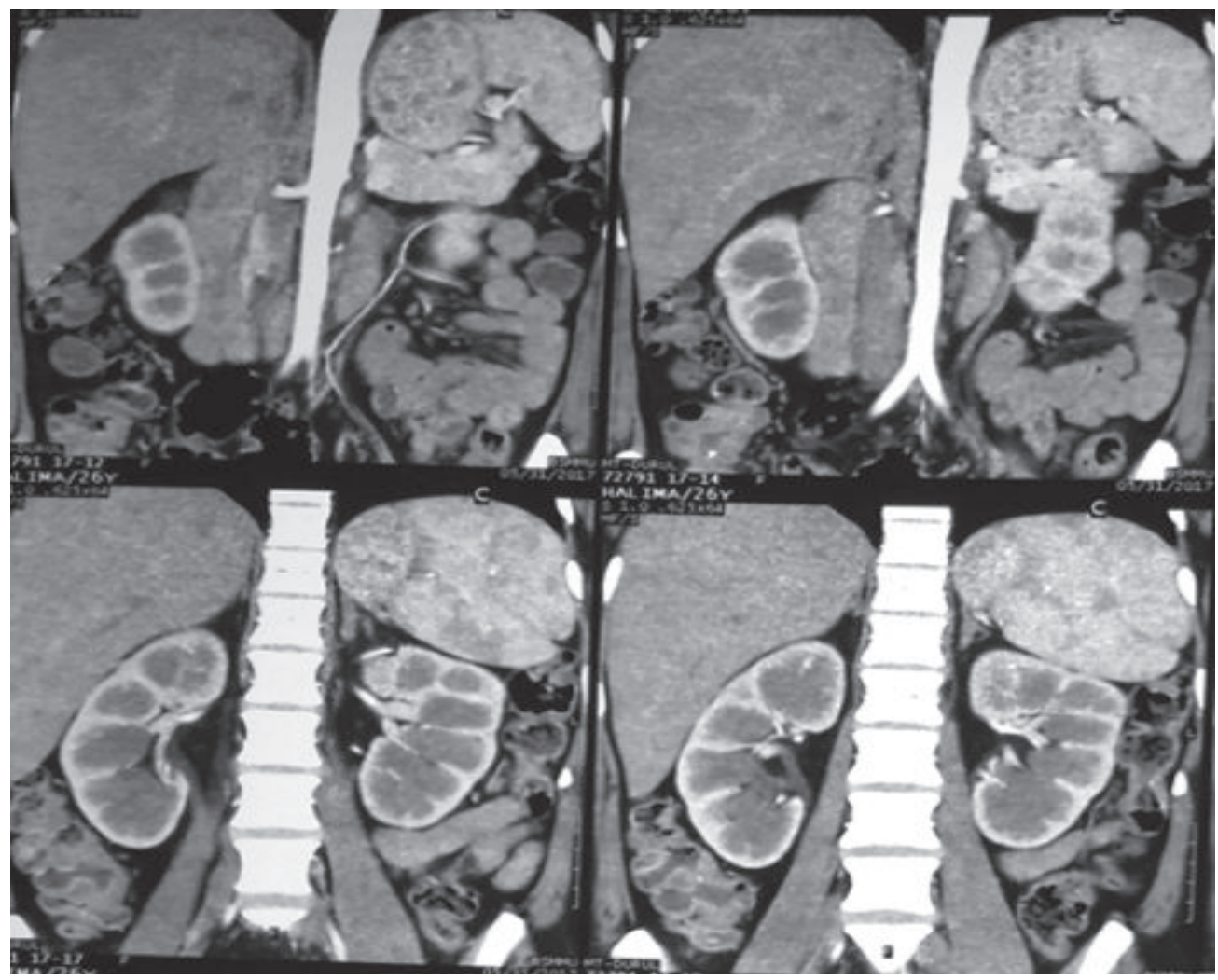

Fig.-2: CT-scan showing left sided adrenal adenoma(arrow marked)

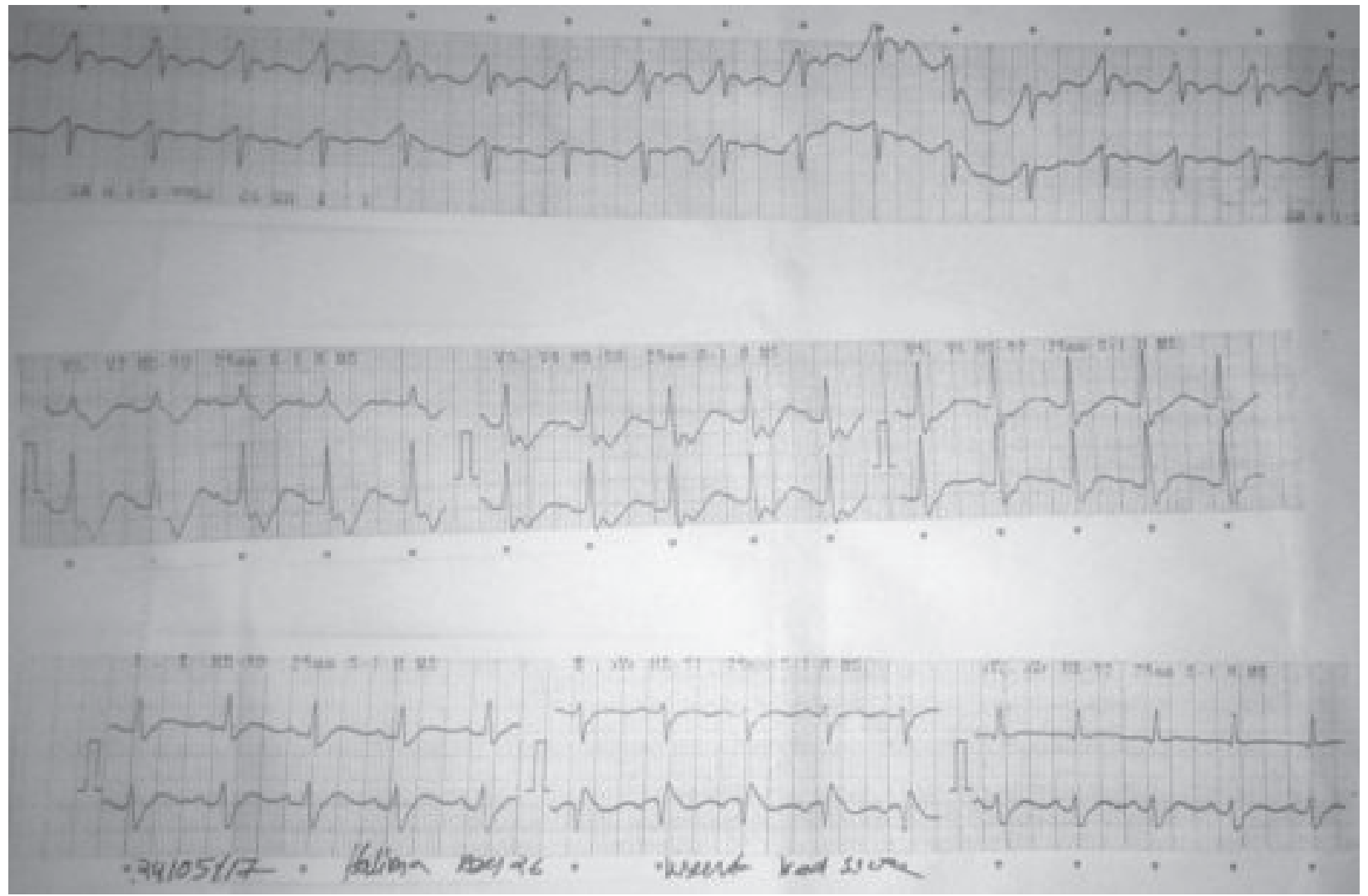

Fig.-1: $E C G$ 


\section{Discussion}

Recent data, suggest that primary hyperaldosteronism as one of the commonest cause of secondary hypertension and commonly occurs between 30 and 50 years of age $3 .{ }^{5}$ Causes of primary hyperaldosteronism unilateral adenoma $(30 \%)$, unilateral $(2 \%)$ and bilateral $(60 \%)$ adrenal hyperplasia, familial hyperaldosteronism (1\%) and adrenal carcinoma with aldosterone hypersecretion $(<1 \%)$. The uncontrollable synthesisof aldosterone leads to increased sodium reabsorption, kaliuresis and renin suppression. All of the above produces arterial hypertension, which affects target organs (heart, kidneys, brain) more severely than essential hypertension does. ${ }^{6}$

Primary hyperaldosteronism is usually associatedwith hypokalemia, renal potassium leakage, and arterialhypertension due to excessive aldosterone secretion. ${ }^{7}$ However, the clinical and biological spectrum of primaryhyperaldosteronism varies. In particular, hypokalemia isuncommon and present only in 7 to $38 \%$ of cases. ${ }^{8}$ Primary hyperaldosteronism can also present as flaccid paraparesis which is more common in Oriental people. ${ }^{8}$ Our patient presented with recurrent flaccid quadriparesis due to hypokalaemia which is a only present in a few percentage of the patient and she had young onset of hypertension.

The diagnostic approach of primary hyperaldosteronism can be summarised in three main steps: plasma Aldosterone Concentration (PAC), plasma Renin Activity (PRA) and calculation of PAC/PRA Ratio calculation. PAC/PRC rates over 23.6 are diagnostic of PA, with a sensitivity of $97 \%$ and a specifcity of $94 \%$. Aldosterone receptor antagonists should be discontinued at least 6 weeks before the examination. ${ }^{9}$ Our patient had a PAC/ PRA ratio of 37.91 which idiagnostic of primary hyperaldosteronism. Confrmation of primay hyperaldosteronism is based on oral sodium load test, saline infusion testand ûudrocortisone suppression test. Oral sodium load test includes the determination of sodium and aldosteroneconcentration in 24-hour urine, after 3 days of increased salt intake. Rates of aldosterone $>12 \quad 1 / 4 \mathrm{~g}$ and Sodium $>200 \mathrm{mmols}$ are diagnostic of PA. ${ }^{9}$ We could not do the test due to unavailability. The ûudrocortisone suppression test is rarely performed in most centers nowadays. ${ }^{9}$

Distinction of the disease subtype is based on CT (MRI shows no superiority), adrenal vein catheterizationwith venous sampling and genetic screening for the familial types of the disease. ${ }^{5}$ In our patient, contrast CT-scan of adrenal glandsdemonstrated unilateral adrenal adenoma
. We could not do venous sampling due to unavailability. The therapeutic approach, in unilateral formsof primary hyperaldosteronism preferably adrenalectomy, while bilateral disease are treated conservatively, with aldosteronereceptor antagonists. ${ }^{10,11}$ Our patient was treated with spiranolactone, titrated up to $100 \mathrm{mg}$ daily and losartan potassium 50mg daily, leading to optimal control of blood pressure and she listed for left sided adrenalectomy.

In conclusion, primary hyperaldosteronism can be presented with diagnostic dilemma to the clinicians because, it has variable presentations. Screening for hyperaldosteronism should beundertaken more frequently in cases of younrg or resistanthypertension, hypertension with spontaneous or secondaryhypokalemia and in patients with hypokalaemic paralysis totreat them effectively. Choice of treatment in unilateral adrenal adenoma with hyperaldosteronism is adrenalectomy but before that patient should be normotensive with medical management.

\section{References}

1. Conn JW: Primary aldosteronism, a new clinical syndrome. J Lab Clin Med; 1955;45:3-17

2. Young WF: Primary aldosteronism-renaissance of a syndrome: Review. Clin Endocrinol; 2007;66:607-18

3. Krysiak R, OkopieD B, Herman ZS: Primary aldosteronism. Przegl Lek; 2007;64(1):31-6.

4. Young WF Jr: Minireview: primary aldosteronism—changing concepts in diagnosis and treatment. Endocrinology; 2003;144(6):2208-13

5. Hannesmann A, Wallaschofski H. Prevalence of primary aldosteronism in patient's cohorts and in population-based studies-a review of the current literature. Horm Metab Res. 2012; 44: 15762

6. Viola A, Tizzani D, Monticone S, Crudo V, Galmozzi M, Burrello J, et al. Diagnosis and treatment of unilateral forms of primary aldosteronism. Curr Hypertens Rev. 2013; 9: 156-65.

7. Vallotton MB: Primary aldosteronism. Clin Endocrinol; 1996;45:4760

8. Conn JW, Rovner D, Cohen E, Nesbit R: Normokalemicprimary hyperaldosteronism. Its masquerade as essential hypertension. $\mathrm{J}$ Am Med Assoc; 1966;195:111-6.

9. Young WF. Primary aldosteronism: renaissance of a syndrome. Clin Endocrinol (Oxf). 2007; 66: 607-18.

10. Sukor N, Gordon RD, Ku YK, Jones M, Stowasser M. Role of unilateral adrenalectomy in bilateral primary aldosteronism: a 22year single center experience. J Clin Endocrinol Metab. 2009; 94: 2437-45.

11. Ronconi V, Turchi F, Appolloni G, di Tizio V, Boscaro M, Giacchetti G. Aldosterone, mineralocorticoid receptor and the metabolic syndrome: role of the mineralocorticoid receptor antagonists. Curr Vasc Pharmacol. 2012; 10: 238-46. 